\title{
Author Correction: A natural experiment study of the effects of imprisonment on violence in the community
}

David J. Harding (D), Jeffrey D. Morenoff, Anh P. Nguyen (D), Shawn D. Bushway and Ingrid A. Binswanger

Correction to: Nature Human Behaviour https://doi.org/10.1038/s41562-019-0604-8, published online 13 May 2019.

This correction clarifies the relationship between the present work and previously published studies using the same dataset. Although the originally published version of this article cited these preceding papers, it did not specifically describe the similarities and differences among the analyses. The data analyzed in this paper were collected as part of a larger project on the causal effects of imprisonment, including on labour market outcomes (reference 67 in the manuscript;) and future imprisonment and felony convictions (reference 51 in the manuscript). Reference 51 did not specifically analyse future violent crime. We have modified the text to explicitly discuss reference 51 and how it relates to the current work. The error has been corrected in the HTML and PDF versions of the article.

51. Harding, D. J., Morenoff, J. D., Nguyen, A. P. \& Bushway, S. D. Short- and long-term effects of imprisonment on future felony convictions and prison admissions. Proc. Natl Acad. Sci. USA 114, 11103-11108 (2017).

67. Harding, D. J., Morenoff, J. D., Nguyen, A. P. \& Bushway, S. D. Imprisonment and labor market outcomes: evidence from a natural experiment. Am. J. Sociol. 124, 49-110 (2018).

Published online: 22 April 2020

https://doi.org/10.1038/s41562-020-0882-1

(C) The Author(s), under exclusive licence to Springer Nature Limited 2020 